\title{
Teaching New Dogs Old Tricks: Membrane Biophysical Properties in Drug Delivery and Resistance
}

\author{
Nina Milosavljevic ${ }^{4}$, Adam Blanchard ${ }^{1}$, Miriam L. Wahl ${ }^{3}$, Salvador Harguindey $^{2}$, Mallorie Poet ${ }^{4}$, \\ Laurent Counillon ${ }^{4}$ and Cyril Rauch ${ }^{1}$
}

\begin{abstract}
${ }^{I}$ School of Veterinary Medicine and Science, University of Nottingham, College Road, Sutton Bonington, LE12 5RD, UK., ${ }^{2}$ Institute of Clinical Biology and Metabolism, c) Postas 13, 01004 Vitoria, Spain, ${ }^{3}$ Department of Chemistry, $U$. Baltimore, Baltimore, MD, USA, ${ }^{4}$ Université de Nice-Sophia Antipolis, Laboratoire Transport Ionique Aspects Normaux et Pathologiques, CNRS UMR 6097, Faculté des Sciences Parc Valrose 06108 Nice Cedex, France
\end{abstract}

Received: January 25, 2011; Accepted: February 20, 2011; Revised: April 13, 2011

\begin{abstract}
How do drugs cross the plasma membrane?" this may seem like a trivial question. This question is often overlooked to focus primarily on the different complex macro-molecular aspects involved in drug delivery or drug resistance. However, recent studies have highlighted the theme that to be fully understood, more knowledge of the underlying biology of the most complex biological processes involved in the delivery and resistance to drugs is needed. After all, why would a drug interact with a transporter then subsequently be excluded from P-glycoprotein (P-gp) expressing drug resistant cells? What are the determinants of this transition in behavior? Full consideration of the physical biology of drug delivery has allowed a better understanding of the reasons why specific membrane proteins are upregulated or overexpressed in drug resistant cells. This, in turn, allows us to identify new targets for drug chemicals. Better yet, it increases the significance of recents patents and underlines their importance in multi drug resistance.
\end{abstract}

Keyword: Cell membrane, drug delivery, drug resistance, pharmacokinetics, physical biology.

\section{INTRODUCTION}

Most of the antitumor agents commonly used in cancer treatment clinics induce their effect by targeting DNA replication, cell division and related mechanisms. These strategies, which are directly aimed at the core of the proliferation process, have led to widely-used antineoplastic treatments to date. Despite positive impact in clinics, these treatments bear intrinsic limitations that in some cases are slowing the pace of therapeutic progress and prompt us to explore new concepts such as those discussed by our colleagues in this special issue. These limitations pertain to the intracellular mode of action of the drugs, the complex and heterogeneous nature of the tumorigenic process, and the multiplicity of causes that can lead to drug resistance [1]. In several cases, it has even been proposed that this can be responsible for the fact that some therapies can even exacerbate the original malignant phenotype, induce suppression of apoptosis, and in fine improve the progression of the disease [1-3].

All of the drugs that are aimed at intracellular targets have to undergo common molecular processes that trigger their partition between the extracellular medium, the bilayer membrane, and the cytoplasm. Therefore, understanding how these drugs can penetrate, accumulate or can be excluded from normal and cancer cells constitutes one of the areas worthy of investigation to optimize classical antitumor

\footnotetext{
*Address correspondence to this author at the School of Veterinary Medicine and Science, University of Nottingham, College Road, Sutton Bonington, LE12 5RD, UK; Tel: +44 (0)115 95 16451; Fax: +44 (0)115 95 16440; E-mails: Cyril.rauch@nottingham.ac.uk; Laurent.counillon@unice.fr
}

treatments, decrease side effects and to better understand drug resistance. This process is summarized in Fig. (1), which shows that three important parameters have to be thoroughly taken into account: (i) membrane properties: packing, charge, potential, and composition, (ii) physicochemical parameters of the drugs: size, hydrophobicity, net charge, $\mathrm{pK}_{\mathrm{a}} \mathrm{s}$ of the protonable groups, and (iii) properties of intracellular spaces: $\mathrm{pH}$, potential, intracellular compartments. In this case, the membrane properties interact with drugs to block their transverse diffusion thereby increasing their ability to diffuse laterally in the membrane (we shall see that this will increase the probability of drug and drug transporter interactions). However, even when drugs traverse the plasma membrane, alterations in cytosolic and vesicular $\mathrm{pH}$ can be enough to trap the drug in specific compartments.

In this review, instead of focusing on new and nongenomic approaches to cancer treatment, which are very well described in other articles, we will revisit the basic principles that govern drug uptake by cells, i.e. accumulation and extrusion. Furthermore, instead of reviewing all drug or membrane complex physico-chemical parameters involved in drug delivery, we shall focus our attention on the role of drug size, membrane mechanical properties - i.e. membrane endocytosis - and, finally, on cytosolic $\mathrm{pH}$. The reason for this specific focus is renewed interest in the role of the plasma membrane's basic biophysical properties. This will lead us to discuss the above-mentioned parameters, and the action of PgP-like proteins that have been thought to function as efflux pumps, as well as the importance of acidic intracellular compartments in the sequestration of protonatable 


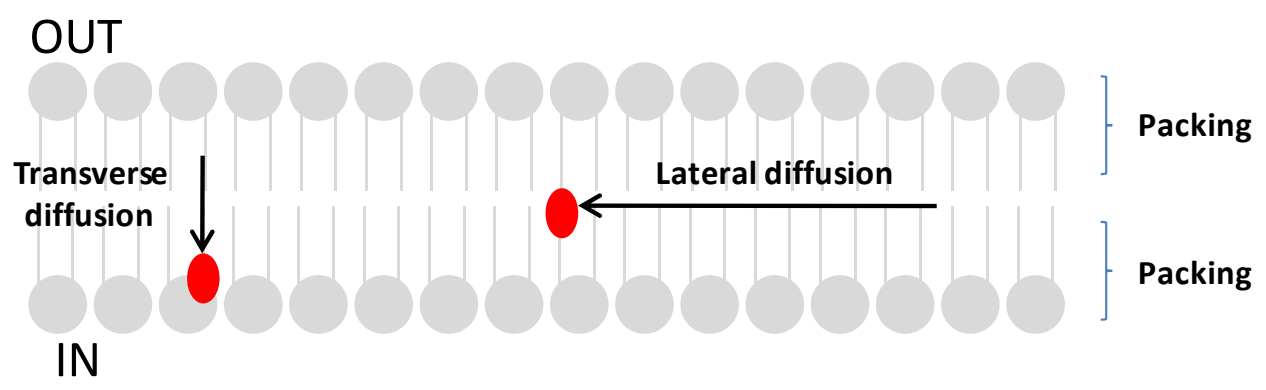

Protonation, pH, pKa, charge

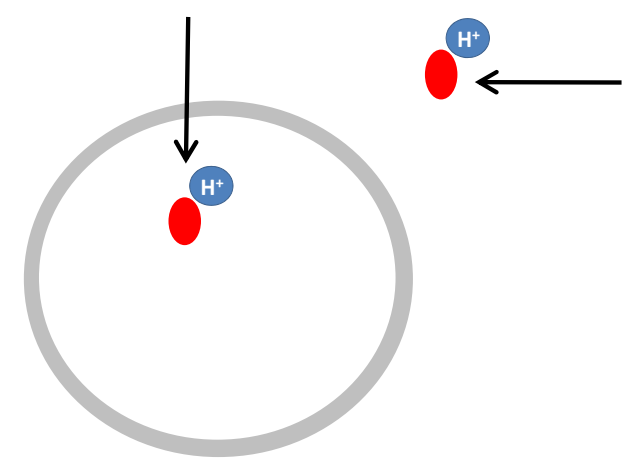

Fig. (1). Summary of the different mechanisms that determine the distribution of a drug from the extracellular side to the membrane space and to the cytoplasm.

drugs. By taking into account the principles of membrane physical chemistry and drug diffusion in a different context, this review will highlight important points that may lead to the design of optimized treatments or better adjunct therapy strategies.

\section{HISTORICAL CONNECTION BETWEEN FLUID PHASE ENDOCYTOSIS AND MEMBRANE PHYSICS: IMPLICATION FOR DRUGS UPTAKE.}

In the introduction, the term endocytosis was associated with the mechanical properties of the plasma membrane. This relationship is central to the understanding of how and why the size of a drug is paramount to determine the mode of delivery. For that reason, it is important to start this review with a few paragraphs explaining how, historically, this connection was made possible.

Fluid phase endocytosis has puzzled scientists for a relatively long time. The reason for this is that membrane vesicles created this way do not require a protein coat, contrary to clathrin coated pits. Accordingly, the motor force remained elusive until it was connected to membrane lipid asymmetry. To introduce how endocytosis is related to the differential packing of lipids, let's consider first a vesicle as is found in living cells Fig. (2A). Once formed, membrane vesicles have a radius of about $R \sim 50 \mathrm{~nm}$ and as the vesicle radius is only ten fold higher than the membrane thickness $(h \sim 5 \mathrm{~nm}), R / h \sim 10$, it is quick to see that the surface area of the outer leaflet is larger than the surface area of the inner leaflet Fig. (2A). Thus, the outer leaflet of a vesicle must have significantly more lipid than the inner leaflet. Assuming that lipids have a cross sectional area $\sim a_{0}$, the difference in lipid number between the outer and inner leaflets ( $\Delta N$ ) is given by $a_{0} \cdot \Delta N \sim S_{\text {out }}-S_{\text {in }}$, where $S_{\text {out }}-S_{\text {in }}$ is the difference between the outer and inner surface area. As this difference is also given by $S_{\text {out }}-S_{\text {in }} \sim S_{0} \cdot h / R$, where $S_{0}$ is defined as the neutral surface area of the vesicle (see Fig. $(\mathbf{2 A})$ ). According to the equations above, it follows that the vesicle radius is, geometrically speaking, inversely proportional to the lipid number asymmetry between leaflets $R \sim 1 / \Delta N$, reviewed in [4]. As the outer leaflet of the vesicle comes from the inner leaflet of the membrane, this result suggests that for a vesicle to be created, more lipids have to be stored in the inner leaflet of the cell membrane, relative to the outer leaflet. This feature has been linked to the way the membrane organize their own lipid composition.

It is well known that lipids are not randomly distributed in the cell membrane, but follow a strict composition between leaflets thanks to a specific lipid enzyme flippase [5]. For example, phosphatidylserine and phosphatidylethanolamine are maintained in the inner leaflet, and actively relocated from the outer to the inner leaflet if needed, by a lipid flippase [6, 7]. The connection between the asymmetry in phospholipid composition of the cell membrane and endocy- 

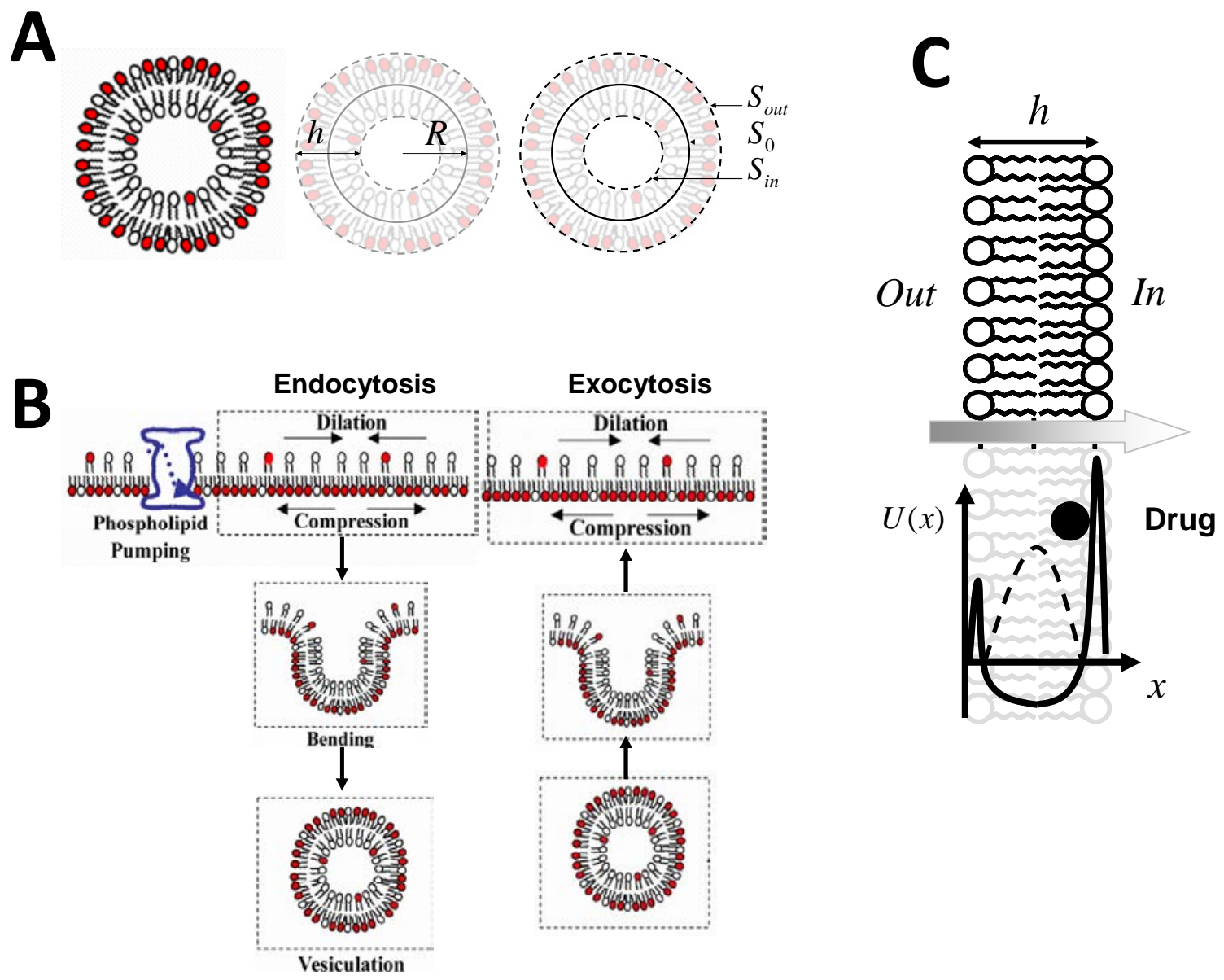

Fig. (2). (A) Lipid asymmetry at the vesicular scale: Given the small size of vesicles, the radius and membrane thickness are relatively close together $(R / h \sim 10)$. Thus, the outer leaflet of a vesicle $\left(S_{\text {out }}\right)$ has significantly more lipid than the inner leaflet $\left(S_{\text {in }}\right)$. As the vesicle is spherical, noting $S_{0}=4 \pi R^{2}$ the neutral surface area namely the surface area between the outer and inner leaflets, it follows at the first order that $S_{\text {out }}=4 \pi(R+h / 2)^{2} \sim S_{0}(1+h / R)$ and $S_{\text {in }}=4 \pi(R-h / 2)^{2} \sim S_{0}(1-h / R)$. Thus $S_{\text {out }}-S_{\text {in }} \sim S_{0} \cdot h / R$. (B) Sketch representing the current model linking fluid phase endocytosis to the membrane phospholipid number asymmetry [6]. In the left panel, the translocation of darkheaded lipids into the inner leaflet induces a differential packing of lipids between leaflets leading to membrane bending and vesiculation $[11,12]$. Note that the membrane recycling that occurs in cells (right panel), i.e. the exocytosis of vesicles with a size similar to endocytic vesicles, allows the maintenance of the lipid asymmetry and thus the maintenance of the differential packing of leaflets at the level of the plasmalemma. The relationship existing between the lipid number asymmetry and the vesicle radius is given by $R=8 k_{c} / h K\left(\Delta N / N_{0}\right)$. Accordingly, the lipid number asymmetry has been experimentally deduced from studies on drug sensitive cells (K562) with a value $\Delta N / N_{0}=4 \%$ providing a $\sim 35 \mathrm{~nm}$ vesicle radius [12]. Note that as the mechanisms of endocytosis and exocytosis are symmetrical to one another, there is no need to pump lipid into the inner leaflet in a continuous way. Indeed, endocytosis and exocytosis taken together ensure a contant lipid asymmetry and constant membrane recycling. This phenomenon is known a dynamical instability in physics[26]. (C) Representation of the different energy barriers (noted together $U(x)$ ) and involved when a drug traverses the bilayer cellular membrane. Two leaflets represent the membrane with an inner leaflet containing more phospholipids related to the increase in the difference in surface tensions (upper graph). Energy profiles of lipid packing in both leaflet (plain curve-lower graph) and hydrophobic core of membrane (dashed curvelower graph) are both involved in providing penalty energies with regard to the transbilayer movement of drugs. As the inner leaflet is packed, drugs crossing the membrane will be trapped in this leaflet which will delay and impair their flow into the cytosol . The latter effect will be dependent on the size of drugs as bigger drugs will "feel more strongly" this mechanical barrier. In the present paper, this effect is supposed to be central for the high levels of cross resistance to drugs that Biedler and Riehm measured.

tosis, including the cell membrane mechanical properties, came in three phases.

First, in well defined model systems it was found that the shape of giant unilamellar liposomes (GUVs) described by physical parameters like the global curvature, could be al- tered by changing the lipid asymmetry between leaflets [8] and that, conversely, by providing an adequate theory based on the mechanical properties of such biomembrane systems (known as the "area-difference elasticity" (ADE) model) it was possible to predict the changes in the GUV's shape as a function of the lipid asymmetry imposed [9]. This first phase 
allowed the connection between membrane shapes and membrane mechanical properties. Secondly, the relationship between the lipid asymmetry and endocytosis came when it was discovered that imposing a sufficient lipid asymmetry in GUVs produced membrane budding [8], this experiment was repeated in cells and it was found that an excess of phosphatidylserine added in the inner leaflet, namely translocated from the outer into the inner leaflet by a flippase activity [6, 10], increases the kinetic of endocytosis [11]. Thirdly, from the connection between living and model systems, it was proposed a theory of endocytosis inspired from the ADE model $[4,12]$. This theory suggests that to generate endocytosis, namely an inward membrane budding, a constant lipid number asymmetry is needed at the level of the cell membrane, maintained by the flippase activity and the membrane recycling Fig. (2B). The underlying physical formulas are given in appendix.

This model was compared to experimental analysis and it was deduced that there exists a lipid number asymmetry in the membrane of eukaryotic cells: $\Delta N / N_{0} \sim 4 \%$, where $N_{0}$ corresponds to the average number of lipid in either leaflet (see appendix) [12]. This theory provides a vesicle radius of $\sim 35 \mathrm{~nm}$ similar to what is observed and measured in living cells. Therefore, this model suggests that endocytosis results from a differential packing of lipids between the inner and outer leaflets of the cell membrane Fig. (2C). Note that it is not because the model focuses on phospholipids that it does rule out the involvement of cholesterol. Since cholesterol partions equally between leaflets, it is not involved in the membrane asymmetry. Regarding the role of lipid rafts, since these are rigid patches, the lipid asymmetry theory does not apply; (they have unique biophysical properties) $[13,14]$.

The role of the differential packing on drugs' membrane permeability can now be addressed. The membrane barrier potential, namely the energy required for a drug to cross the membrane, is a complex function of the set of interactions between a drug and the membrane components, which varies along the membrane thickness. Initially, drugs are expected to insert the outer leaflet by optimizing their energy (i.e. chemical potential). Thus, the hydrophobic (non polar) part of the drug is presumed to be present in the hydrophobic core of the membrane. Resulting from this assumption is the fact that to incorporate totally the inner leaflet and to traverse the bilayer, the drug must transfer its hydrophilic (polar) part in the hydrophobic core (i.e. oily phase) of the membrane. This process corresponds to the dehydration of the drug. This will inevitably lead to a penalty energy that usually prevails in the middle of the membrane (dashed curve in Fig. (2C)), and that shall be noted: $E_{\text {hydra }}=\Delta G$. Note however that this penalty energy will remain constant when a cell switches its state from drug sensitivity to resistant, as it is related to the physico-chemical properties of the drug.

Finally, to pass through the membrane the drug will also have to bypass the barrier energy linked to the differential packing of lipids. This penalty energy is maximal at the level of polar heads, where the repulsion between lipids dominates (plain curve in Fig. (2C)). As a result, large drugs will feel the packing more strongly because they are more "squeezed". It can be demonstrated that this energy is: $a \cdot K \cdot \Delta N / N_{0}$, where $a$ is the cross section area of the drug intercalated in the membrane, $K$ the elastic modulus of the membrane and " $\Delta N / N_{0}$ " the lipid asymmetry (see appendix). Note that contrary to the former penalty energy, the lipid packing is expected to be increased in the drug resistant state, given the higher kinetic rates of endocytosis measured in drug resistant cells, see [15-17] and references within. In addition, given that the spatial dimension of the drug is involved (i.e. " $a$ "), this means that the size of the drug, or equivalently its molecular weight (MW), is central. Providing that the lipid packing difference is related to the fluid phase vesicle radius, the mechanical energy $a \cdot K \cdot \Delta N / N_{0}$ can be rewritten as:

$$
E_{\text {mech }}=a \frac{8 k_{c}}{h R}
$$

Where $k_{c}$ is the bending modulus of the membrane (see appendix). Contrary to the lipid asymmetry that has not been measured directly in living systems, the later relation diplay more amenable variables including membrane thickness, vesicle radius and membrane bending modulus that can be measured directly. With Eq.1, the impact of membrane lipid asymmetry on drugs size exclusion can be, at least in theory, studied.

\section{THE CRITICAL PARAMETERS THAT GOVERN DRUG DIFFUSION ACROSS MEMBRANES}

One thing that comes directly from the above equation is that because large drugs have difficulty to cross the membrane, they will remain in the membrane for longer. This point is clearly indicated by the measure of diffusion coefficients of drugs in biomembranes. Indeed, classical anticancer drugs have a relatively small apparent diffusion coefficient through biomembranes $\sim 10^{-6} \mu \mathrm{m}^{2} / \mathrm{s}$ [18]. In water however, the same coefficient is $\sim 10^{2} \mu \mathrm{m}^{2} / \mathrm{s}[19,20]$, which gives a ratio in the diffusion coefficients of eight orders of magnitude. Such a difference is explained by the intrinsic energy needed for a drug to traverse the membrane.

Finally, using Arrhenius's Law, the residency time of drugs in the membrane can be written explicitly to demonstrate that it will be influenced by the biophysical properties we have dealt with from the start, namely dehydration and membrane mechanics:

$t_{0} \sim e^{\frac{E_{h y d r a}+E_{\text {mecha }}}{k_{B} T}}=e^{\frac{\Delta G}{k_{B} T}+8 \frac{k_{c} a}{k_{B} T h R}}$

$k_{B}$ is Boltzmann's constant and $T$ the absolute temperature. From Eq.2, it follows that the time required for the transbilayer movement of drugs is, now, exponentially dependent of of the drug cross sectional area in membrane. Noticeably, this enables to define a critical value for the drug cross sectional area $\left(\mathrm{a}_{\mathrm{c}}\right)$ which yields an important connexion between membrane biophysics and drug size that will be later para- 
mount to understand multi drug resistance (MDR). Noting $a_{c}=h R k_{B} T / 8 k_{c}$. If $a>a_{c}=h R k_{B} T / 8 k_{c}$, the exponential function will be numerically high, meaning that in other words the difference in lipid packing will impair the drug transbilayer movement (the drug will stay in the membrane for longer). A numerical value of $a_{c}$ can be determined: considering a membrane thickness $h \sim 5 \mathrm{~nm}$, a vesicle radius $R \sim 35 \mathrm{~nm}$ determined for drug sensitive cells [12] and a membrane bending modulus, $k_{c} \sim 2.10^{-19} J$ [21], it follows $a_{c} \sim 0.4 \mathrm{~nm}^{2}$ at $37^{\circ} \mathrm{C}$ (Figure 3A). Assuming legitimately that the MW of the drug is proportional to its Van der Waals volume (expressed in $\dot{A}^{3}$ ), a critical MW can also be deduced $M W_{c}=(4 / 3 \sqrt{\pi})\left(h R k_{B} T / 8 k_{c}\right)^{3 / 2} \sim 240$ Fig. (3B), providing a law with regard to the drug size (or MW) selectivity on its permeation across the cell membrane. As a result it can be expected that modifications of lipid packing may produce resistance or sensitivity, depending whether the mechanical packing is amplified or diminished.

It is worth noting that the local membrane budding which leads to membrane vesiculation and controls the kinetics of endocytosis has been associated with an endogenous higher compression of the cellular membrane inner leaflet $[11,12$, $22,23]$. Therefore, another concept that can be derived from the previous equations is that modifications of membrane lipid packing that retroact on drug permeation also affect the radius of fluid phase endocytosis, which constitutes an easy readout for inner leaflet packing. Accordingly, changes have been noted regarding the cellular membrane of MDR cells. In particular, higher rates of endocytosis have been measured $[24,25]$. As the kinetics of endocytosis is inversely proportional to vesicle radius [26], it follows that the mechanical interaction between a drug and the membrane can be rewritten as: $8 k_{c} a / h R k_{B} T=\left(M W / M W_{c}\right)^{2 / 3} \cdot k / k_{0}$. Thus Eq.2 can be rewritten as:

$$
t_{0} \sim e^{\frac{\Delta G}{k_{B} T}+\left(\frac{M W}{M W_{c}}\right)^{2 / 3} \cdot \frac{k}{k_{0}}}
$$

where $k_{0}$ and $k$ are the rate of endocytosis when cells are sensitive (subscript "0") and resistant to drugs respectively. Note that as endocytosis and exocytosis are symetrical to one another (see legend Fig. (2B)) and thus, changes in the cellular volume is not an option. If we assume that the membrane barrier energy will prolong the turnover time of the drugs that have partitioned in the membrane, they are expected to diffuse laterally, which may in turn increase the probability that they bind to and are extruded by a Pgp-like transporter.

So far we have determined how the time of residence of drugs in the cell membrane is determined by a complex molecular dialog between the drugs features and the membrane physical properties. We will now add a level of complexity by discussing how these factors are determining the interaction with drug transporters.
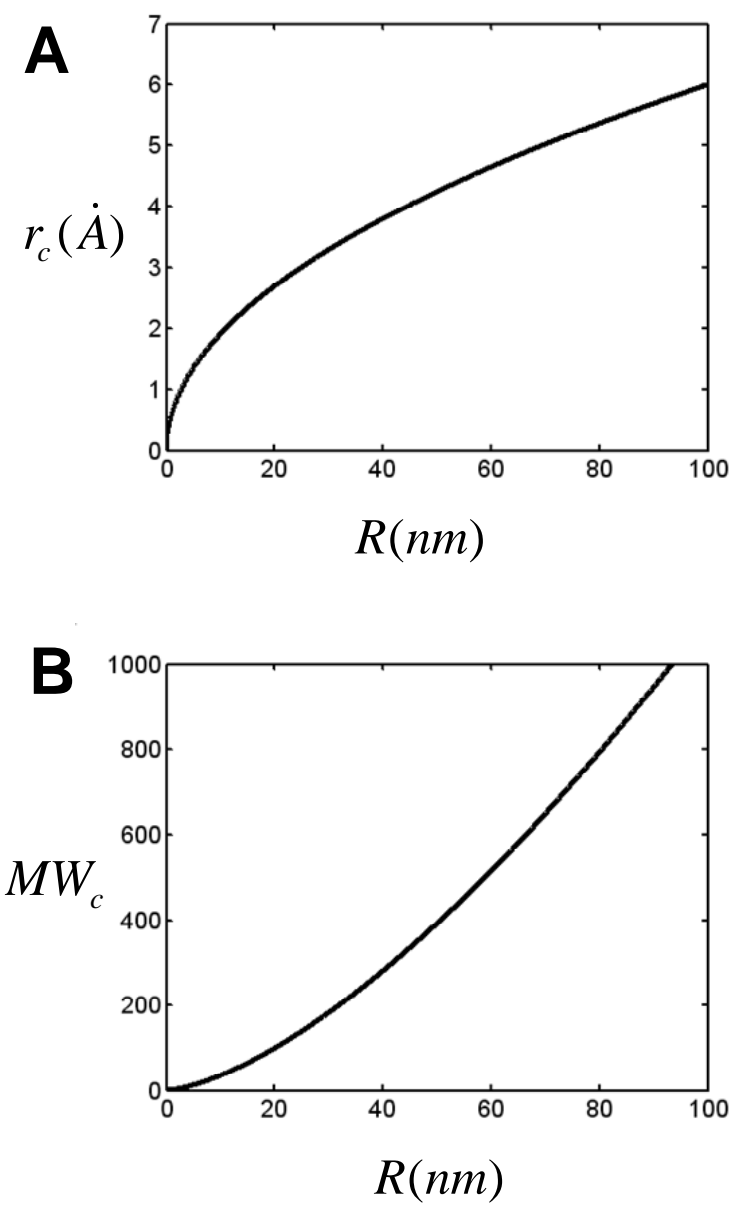

Fig. (3). (A) Relationship existing between the drugs' Van der Waals radius, $r_{c}(\dot{A})$ and their ability to bypass the membrane barrier as a function of vesicular radius, $R(\mathrm{~nm})$ (i.e. function of the difference in surface tension), scaling as $r_{c} \sim R^{1 / 2}$ [exactly: $\left.r_{c} \cong 0.6 R^{1 / 2}\right]$. (B) The existing relationship between the MW of drugs and their ability to bypass the membrane barrier as a function of vesicles radius $R(n m)$, scaling as $M W_{c} \sim r_{c}^{3} \sim R^{3 / 2}$ [exactly: $\left.M W_{c}=4 \pi r_{c}^{3} / 3 \cong 1.1 R^{3 / 2}\right]$.

\section{MULTIDRUG RESISTANCE AND PGP-LIKE TRANSPORTERS}

Let us assume a homogeneous lipid bilayer membrane. Pgp-like transporters are integral plasma membrane proteins that have been presumed to impair the intracellular accumulation of drugs by extruding them at a rapid rate from the plasma membrane inner leaflet, before they reach the cytosol [27-37]. It follows that the efficiency of Pgp-like transporters to mediate MDR should rely on the rates of lateral diffusion of drugs from their initial incorporation in plasma membranes to the transporters prior to extrusion. The longer the lateral path of diffusion before a drug is released into the 
cytoplasm, the higher the probability of a drug binding to a transporter. Taken together, these different aspects point to the need to add supplementary dimensions to the "vacuum cleaner" model in which PgP functions as simple efflux pumps in a 2 dimensional membrane system. We will now address them by exploring additional factors related to the membrane physical properties. We will see that in this process we may have to take into account a supplementary set of parameters: intracellular and extracellular $\mathrm{pH}$.

\section{When Drugs Meet Pgp}

Let us assume that: (i) the number of Pgps on the cellular surface of MDR cells remains globally constant so that the surface density, $\rho_{P g p}$, is also constant (where $\rho_{P g p}=N_{P g p} S_{P g p} / S_{\text {cell }}$ with $N_{P g p}, S_{P g p}$ and $S_{\text {cell }}$ representing the number of transporters, the cross section area of transporters and the cellular surface, respectively); (ii) the lateral diffusion time of integral plasma membrane Pgp-like transporters can be considered negligible when compared to the lateral diffusion time of much smaller drugs; and (iii) the probability of two drugs interacting with a given transporter at the same time is negligible.

Let us consider the lateral diffusion path noted: $L$. The spatial extent of the lateral diffusion is linked to the residency time of the drug in the membrane, given by Eq.3. More explicitely, as the diffusion takes place, the lateral membrane surface area visited by the drug is: $L^{2} \sim D t_{0}$. Using the surface density of transporters, under these conditions it is possible to demonstrate that the probability of the event "drug meeting a Pgp" in the membrane, $p_{P g p}$, is [38]:

$$
p_{P g p} \sim \rho_{P g p} L^{2}
$$

However, coming into contact with a Pgp is not enough and Pgp-mediated drug extrusion requires the location of the drug in the inner leaflet of the plasma membrane. Eq.4 has to be corrected for this. It can be demonstrated that the probability that a drug enters the inner leaflet can be approached by Maxwell-Boltzmann's distribution, written as: $e^{-\Delta G / k_{B} T}$. As Pgp molecules and drugs have a low specificity toward one another and that lipophilic drugs have a better tendency to interact with Pgps, one can assume that when entering the inner leaflet and meeting a transporter a drug is extruded. In these conditions, the probability, $\tilde{p}_{P g p}$, that a drug is effectively expelled from the membrane by a transporter becomes finally: $\tilde{p}_{P g p} \cong e^{-\frac{\Delta G}{k_{B} T}} p_{P g p}$. From the later equation, it follows that a membrane-embedded drug will inevitably meet a drug transporter only if $\tilde{p}_{P g p}=1$. With this condition and by using Eq.4, it is thus possible to determine the critical surface density of transporters $\rho_{P g p}^{c}$ to generate MDR through the vacuum cleaner mechanism:

$\rho_{P g p}^{c} \sim e^{-\frac{k}{k_{0}} \cdot\left(\frac{M W}{M W_{c}}\right)^{2 / 3}}$
It is worth noting that when the mechanical effect becomes dominant, namely when the drug MW is large (MW $>240)$ or when the kinetics of endocytosis is steadily increased as cells become resistant to drugs, then the surface density of Pgp-like transporters needed to trigger drug resistance is predicted to be low. Doxorubicin with a MW of 545 can be used as an example. Assuming that the kinetics of endocytosis is increased 4-fold in the MDR state (which remains a realistic value in MDR, reviewed in $[24,39,40]$ ), it follows that the surface density of Pgp required would only represent a small fraction $\sim 0.1-1 \%$ of the cellular surface area [15]. This means that as the inner leaflet packing increases, the number of Pgp transporter potentially needed that will encounter and extrude drugs can decrease in an exponential way. Thus, paradoxically, if the main activity of Pgp is to handle drugs, then most of them are expected to be functionally ineffective in MDR.

Finally Eq.5 agrees at least in principle with seminal studies demonstrating that drug size is important in MDR [41-44]. MDR assays measure the effective dose (ED), defined as the ability of drugs to kill $50 \%$ of a cell population (that is related to drug influx). EDs can be determined theoretically. The ability of any classical drug to kill a cell is dependent on its ability to cross the membrane. In this context, providing that we know the probability that a drug is not extruded by Pgp, i.e. $1-\tilde{p}_{P g p}$, and the drug residency time within the membrane, $t_{0}$, it is possible to demonstrate that the ratio between the effective doses (EDs) in the sensitive and resistant states can be written as:

$$
\begin{aligned}
& \ln \left(E D_{M D R} / E D_{\text {non-MDR }}\right) \cong\left(M W / M W_{c}\right)^{2 / 3} . \\
& \left(k / k_{0}-1\right)-\ln \left(1-\rho_{P g p} / \rho_{P g p}^{c}\right)
\end{aligned}
$$

Eq.6 shows that although the inhibition of the transmembrane flow of drugs going into the cellular cytoplasm can be performed through the expression of Pgp-like transporters, i.e. when $\rho_{P g p}=\rho_{P g p}^{c}$, the transmembrane flow of drugs can also be reduced exponentially as a function of the kinetics of endocytosis. Furthermore, it emerges a universal power law (i.e. 2/3) that describes the drug/membrane mechanical interaction, and is directly related to the MW of the drug used. Eq.6 demonstrates that if the theory presented here is correct, then the ability of drugs to cross the cell membrane should follow a power law as a function of their MW. Thus, it should be possible to test the validity of the theory proposed. Indeed, Fig. (4) shows a very good correlation between the neperian logarithm of the lethal doses ratio and that of the molecular weigth of a set of anticancer drugs.

So far, we focused on basic membrane biophysical properties and found out their importance in MDR. Another important variable is the cytosolic $\mathrm{pH}$ also aletered when cells switch their state from sensitive to resistant. We will see in the next that an interaction between cytosolic $\mathrm{pH}$ and membrane mechanics is also possible, hence explaining part of MDR. 

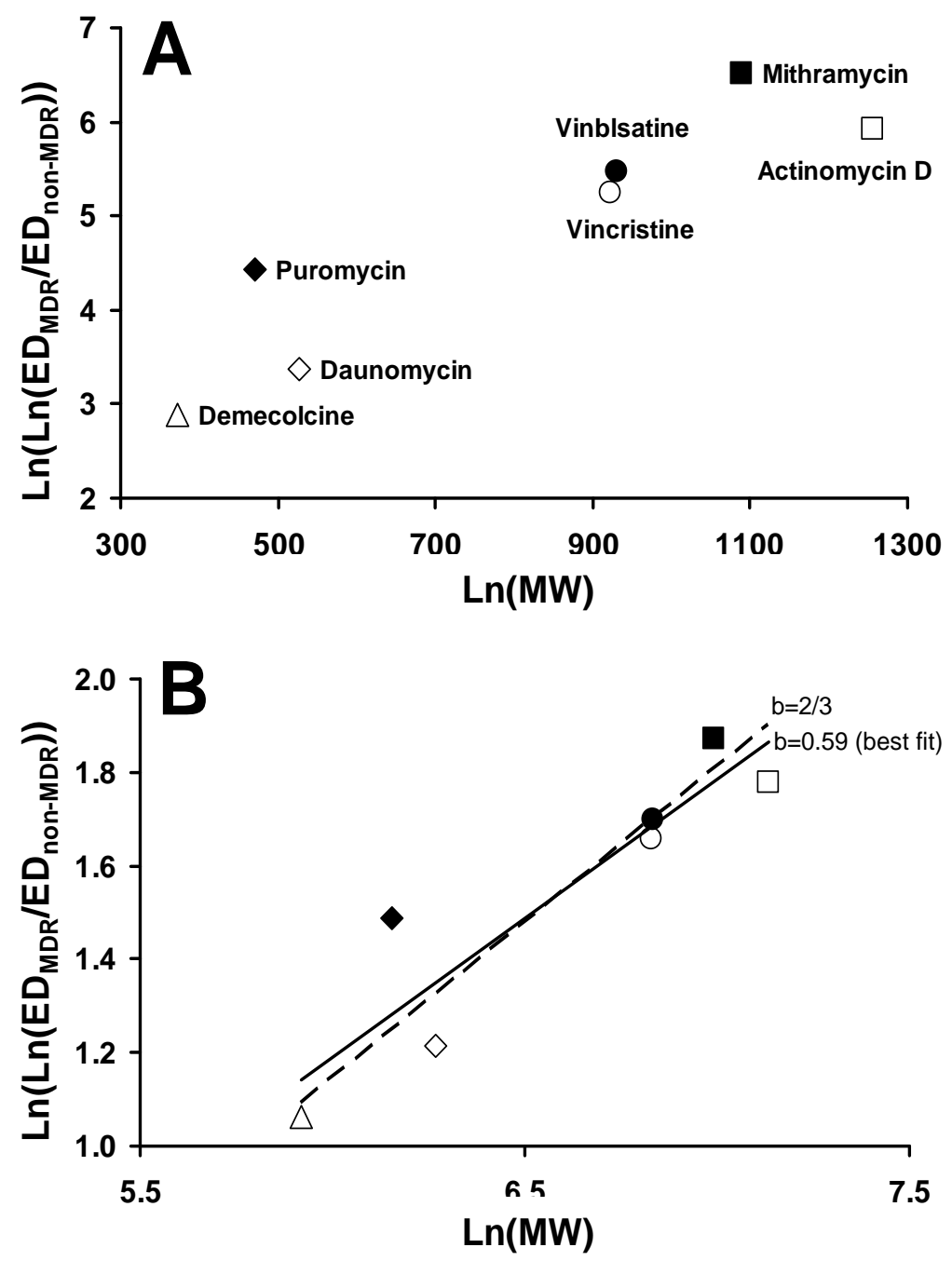

Fig. (4). (A) Drug resistance levels mediated by drugs' molecular weight. Eq.6 explains MDR when both drug properties (MW and dehydration energy) and transporter surface density are fixed. When cross resistance to drugs is considered the surface density of transporters may not be adequate to expel another drug with different physical properties. This scenario would be true if a smaller drug (i.e. low MW) than the one used to select the resistant phenotype is used, as it would cross the membrane more easily, which would decrease the probability of interaction between a drug and a transporter. At constant P-gp expression Eq.6 predicts that the influx of drugs into the cytosol would be chiefly dependent the MW/volume of drugs. The role of drug sizes involved in MDR was initially discovered in 1970 [41]. The authors generated a resistant cell line by selective incubation with actinomycin D (MW=1255) for several months, which led to expression of Pgp transporters. As a second step, they measured cross resistance levels using several other drugs (MW<1255). They measured how both resistant and sensitive cell lines would respond to various drugs. Eq.6 predicts: $\ln \left(E D_{M D R} / E D_{n o n-M D R}\right) \sim\left(M W / M W_{c}\right)^{2 / 3} \cdot\left(k / k_{0}-1\right)$. The numerical data from Bielder and Riehm's study are plotted in (A). (B) Power law of cross resistance to drugs. In order to determine whether a power law involving the MW exists, a double Neperian logarithm was applied to Bielder and Riehm's data and it was found that, indeed, a power law $\sim 0.59 \pm 0.11$ ( $\mathrm{b}=0.59$, plain curve) can be determined, which is similar to the one suggested by the drug/membrane mechanical interaction $\sim 0.66(2 / 3 \sim 0.66)(\mathrm{b}=2 / 3$, dashed curve) $(\mathrm{B})$.

\section{WHY IS pH IMPORTANT?}

\section{The Proton Paradox in Cancer Cells}

Regardless of their origin and genetic background, cancer cells and tissues have been found to diplay an abnormality called "proton reversal" which consists in an interstitial acid microenvironment secondary to an initial, specific and etiopathogenic intracellular alkalosis [45-49]. Inasmuch, a failure to induce intracellular acidification has been proposed to be the main factor underlying drug resistance, and including resistance to the induction of therapeutic apoptosis, in both highly alkaline cancer cells and in malignant cells with a normal or slightly elevated intracellular $\mathrm{pH}\left(\mathrm{pH}_{\mathrm{i}}\right)$ [50-54]. First, a slightly alkaline $\mathrm{pH}$ has be envisioned as a permissive factor for growth and, in second, anticancer drugs that are weak cations will be less protonated and therefore less retained in the intracellular spaces at a more alkaline $\mathrm{pH}_{\mathrm{i}}$ [54-65]. To exemplify these points, one of the most representative and seminal findings in this area has been the ob- 
servation that $\mathrm{pH}$ alkalization from an intracellular $\mathrm{pH}\left(\mathrm{pH}_{\mathrm{i}}\right)$ of 7.0 to $\mathrm{pH}_{\mathrm{i}} 7.4$ triggers a 2000 -fold increase in adriamycin resistance in human lung cancer cells [66]. This level of resistance can be reversed by cellular acidification via administration of verapamil [66]. In parallel studies, the intracellular concentration of adriamycin was shown to be increased by more than 100 -fold after inducing cellular acidification [67].

The relations between extrusion pumps and $\mathrm{pH}$ are more controversial. Several authors have shown that PgP might itself work as an ATP-dependent proton transporter, while others reported that $\mathrm{pH}$ changes, either extracellular or intracellular, have no significant effect on drug extrusion by Pglycoprotein [68-70].

Because inner leaflet lipids bear protonatable polar heads, $\mathrm{pH}$ changes will modify their net charge. In turn this will impact the sum of electrostatic repulsions and modify membrane tension. Based on the previous considerations we will now explore whether, in addition to its other effects, intracellular $\mathrm{pH}$ might also influence drug membrane permeation through modifications of membrane packing and tension.

\section{Cytosolic pH and lipid packing}

To consider any effect of the $\mathrm{pH}_{\mathrm{i}}$ on lipid packing, it is central to understand the notion of packing from a physics standpoint. At a constant membrane surface area, the lipid packing is given by the optimal area per lipid in the cell membrane. The latter is deduced from the balance between repulsions that occur mostly through electrostatic effects on the polar heads, and attractions, which concern more the hydrophobic and geometric effects that take place between the aliphatic chain(s). Any changes in this balance are expected to affect the optimal area per lipid (i.e. their packing) and membrane shape. As a non negligible fraction of the inner leaflet consists in negatively charged lipids, such as phosphatidylserine or $\mathrm{PIP}_{2}$, for example [71] and that these lipids might also be organized in clusters, a slight increase in proton concentration around neutrality (e.g. decrease in $\mathrm{pH}_{\mathrm{i}}$ ) will eliminate or shield these negative charges and decrease the electrostatic repulsion between polar groups. Although such an electrostatic counterion effect might be in principle generalized to intracellular cations, it is obvious that exchangeable protons will have a more pronounced effect on negatively charged lipids. As a final result, a low $\mathrm{pH}_{\mathrm{i}}$ is more likely to be central in abolishing the physical repulsion between lipids, and thus decreases the surface tension (i.e. the lipid packing of the cytosolic leaflet - note that both lipid packing and surface tension are proportional to each other). Such a relationship between free electrolytes and the cross section area per lipid in model biomembranes is well known experimentally [72-74]. Conversely, when the cytosolic $\mathrm{pH}$ increases (i.e. when cells become resistant to drugs in our case), fewer positive charges will be available to mask the lipids charge, which in turn is expected to increase their repulsions and thus their packing. Thus, this higher lipid packing would increase the surface tension of the leaflet in contact with the milieu of elevated cellular $\mathrm{pH}$ in the case of drug resistant cells. So, if the $\mathrm{pH}$ affects the packing of lipids, and the packing of lipids affects the intracellular accumulation of drugs, it follows that the cytosolic $\mathrm{pH}$ should affect the intracellular accumulation of those drugs. As a result, the changes in $\mathrm{pH}_{\mathrm{i}}$ observed when cells switch their state of resistance may be an important clue for understanding the observed alterations of intracellular accumulation of drugs as a function of their sizes. In due course, this could provide a strong argument for the unification of the fields of drug bioavailability and drug resistance. As the packing of lipids is involved, we may expect that the endocytosis kinetic will also be affected by $\mathrm{pH}_{\mathrm{i}}$.

In these conditions, it is possible to demonstrate that if the $\mathrm{pH}$ is involved, then the ratio between effective doses in MDR and non-MDR states should be written as follows [16]:

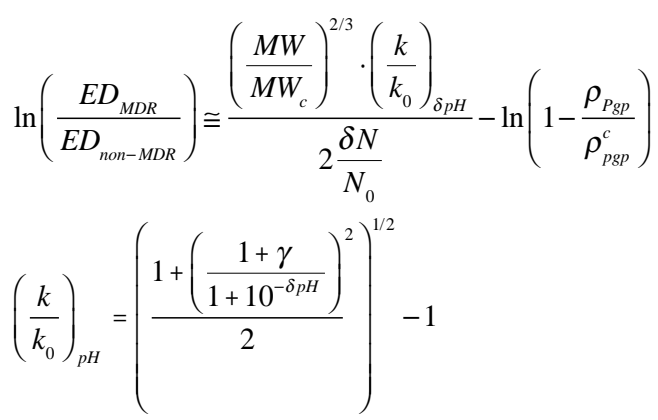

Where $\delta p H=p H_{M D R}-p H_{\text {non- } M D R}$ is the cytosolic $\mathrm{pH}$ difference between the MDR and non MDR states, and $\gamma \cong 1.5$ is a physical constant. The effect of Pgp mediated drug extrusion will be dominant only if $\rho_{P g p} \sim \rho_{P g p}^{c}$ (in which case the Neperian logarithm becomes infinite). Note however that when the EDs are determined, the amount of drug added to cells is necessarily higher than the concentration of the same drug in culture condition and that is used to maintain the resistant phenotype. Therefore, full drug resistance is never reached when the effective doses are determined. It means therefore that when the effective doses are determined: $\rho_{\rho_{g P}}<\rho_{P_{g P}}^{c}$ and that in the last term can be omitted. Eq.7 can be plotted against experimental data issued from different studies. Accordingly, it is possible to demonstrate the correlation between Eq.7 and the experimental data obtained with doxorubicin Fig. (5A). This strongly suggests that effectively, the lethal doses are clearly dependant on cytosolic $\mathrm{pH}$, as predicted in our model.

\section{Drugs in Vesicles: Keeping the Poisons Safely Inside}

If drugs are blocked at the level of the membrane because of an excessive lipid packing (due to higher cytosolic $\mathrm{pH}$ ) then, drugs will follow membrane endocytosis. As a result, drugs will flow into single membrane organelles. This point is central as it can be related to the role of drug $\mathrm{pK}_{\mathrm{a}}$ in MDR and acidic luminal $\mathrm{pH}$ of organelles.

Despite proving to be a useful simplification, considering a mammalian cell as a finite volume surrounded by a single lipid bilayer might be too reductionist to provide with an adequate depiction of drug cellular distribution. Indeed, a 

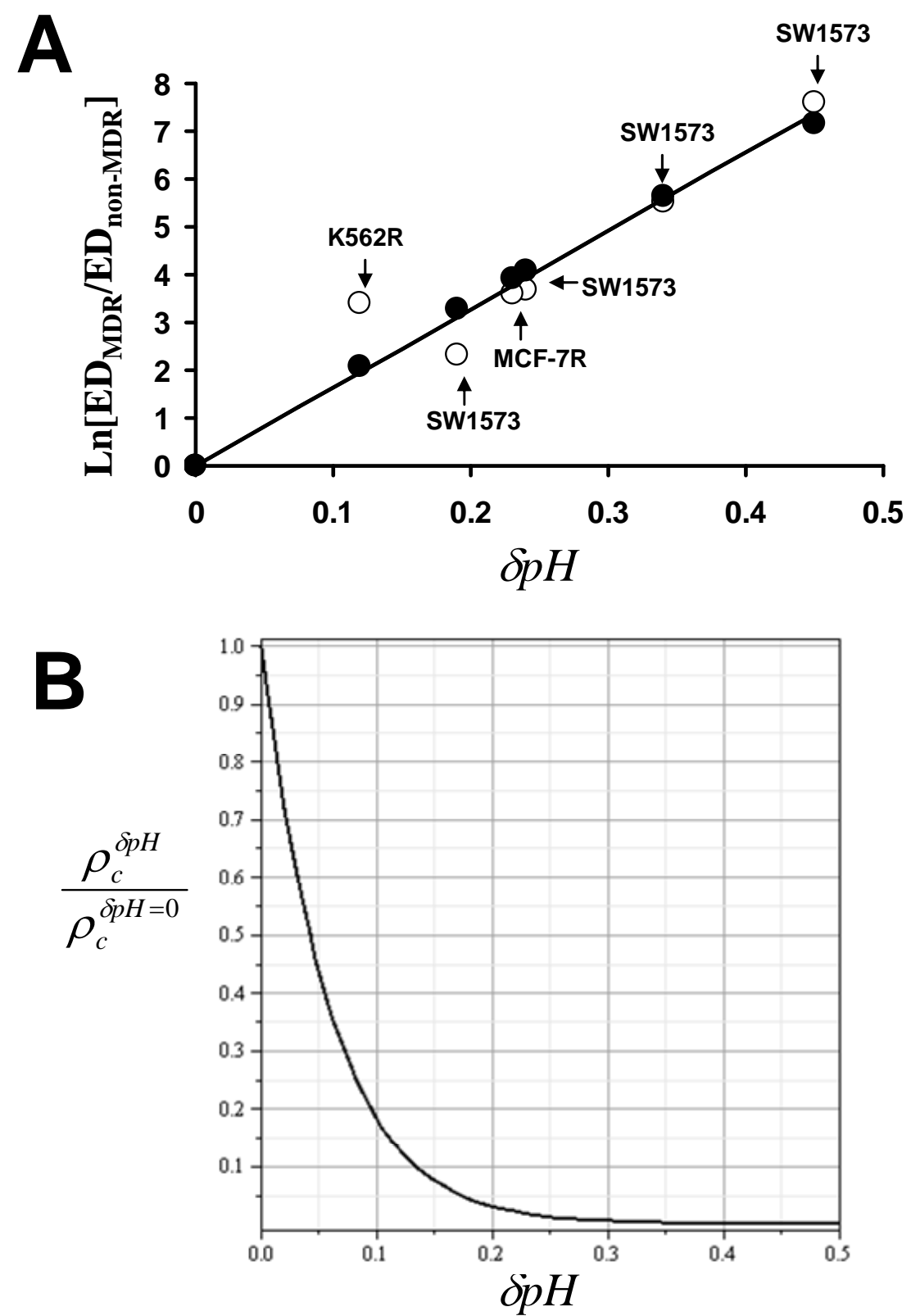

Fig. (5). (A) Comparison between experimental (blanked circles) doxorubicin resistance levels obtained in cells and the theory (filled circles) with $\delta N / N_{0}=2 \%$ (note that this value concerning the lipid asymmetry was determined previously [12]). The open circles corresponding to SW1573 (lung derived cancer cells), K562R (leukemic cancer cells) and MCF-7R (breast derived cancer cells) are indicated with arrows and labels. Finally the straight line is the linear regression of experimental data which agrees very well with the theory. (B) Effect of pH changes (cytosolic alkalization) on the surface density of Pgp transporters needed to trigger drug resistance. As seen in the figure the number of Pgp can decrease exponentially when the $\mathrm{pH}$ increases: the membrane takes over.

large part of the eukaryotic cytoplasm is occupied by singlemembrane organelles, including Golgi apparatus, early and late endosomes, secretory vesicles, lysosomes that have specific characteristics including an acidic luminal $\mathrm{pH}$ which is crucial for fulfilling their cellular functions. Maintaining a low $\mathrm{pH}$ in the compartments of the secretory pathway is necessary for posttranslational protein-modifications and sorting of newly synthesized proteins and lipids through packaging and processing of secretory vesicles to their final destinations [75-77]. Likewise, keeping optimal $\mathrm{pH}$ through the endocytic pathway is essential for receptor-mediated endocytosis and directing internalized molecules towards either recycling or degradation [75, 78-81].

The optimal $\mathrm{pH}$ in organelles is regulated by the balance between active $\mathrm{H}^{+}$pumping and passive $\mathrm{H}^{+}$efflux. Vacuolar proton-translocating ATPase (V-ATPase) has a central role in active pumping of protons and generating acidic luminal $\mathrm{pH}$. Since V-ATPase is electrogenic, the translocation of positive charge $\left(\mathrm{H}^{+}\right)$in lumen generates a large membrane potential which can lead to inhibition of the enzyme's further activity. Also, in some organelles V-ATPase activity can be interfered by presence of other transporters and channels that 
increase the membrane potential (such as $\mathrm{Na}^{+}-\mathrm{K}^{+}$-ATPases in early endosomes). This can also have a negative influence on achieving desired $\mathrm{pH}$ [82-85]. On the contrary, the counterion current is responsible for shunting voltage in organelles and therefore allowing proper V-ATPase activity. This current is primarily mediated by chloride channels including members of the CLC family and possibily the CFTR channel (cystic fibrosis transmembrane conductance regulator) [86-90].

The existence of this steady-state $\mathrm{pH}$ reflects a ratio between $\mathrm{H}^{+}$influx and $\mathrm{H}^{+}$efflux, which indicates that proton leak is another important factor in maintaining organellar homeostasis. Several candidates for this leak have been proposed. These include voltage-gated proton channels, [91, 92], anion exchangers that can facilitate the intake of hydroxyl or bicarbonate ions, or members of the NHE family $\left(\mathrm{Na}^{+}-\mathrm{H}^{+}\right.$exchanger). The progressive decrease of $\mathrm{pH}$ in the secretory and endocytic pathways is achieved by the gradual increase of the V-ATPase density and at the same time decrease of the vesicular $\mathrm{H}^{+}$permeability [93].

Interestingly, it has been shown that in transformed cells the existence of an acidic cytoplasm is coupled to an abnormally alkaline organellar $\mathrm{pH}$ [94]. For instance, the rastransformed fibroblasts show significantly higher $\mathrm{pH}$ in lysosomes compared to the nontransformed parental cells [95]. This provides with an important clue to explain the greater sensitivity of cancer cells to antineoplastic agents when compared to normal cells, which makes the treatments possible in patients. In normal cells, these weak base drugs (pKs of 7-8) are sequestered by acidified organelles, while cells that have a higher organellar $\mathrm{pH}$, are not able to sequester them as well, and are therefore more sensitive. Interestingly, drug-resistant tumor cells have restored organellar $\mathrm{pH}$, and like normal cells can significantly reduce the accumulation of chemotherapeutic drugs in the cytosol and nucleus compared to drug-sensitive cells [94]. Because sequestration of protonable drug is a complex partition mechanism, it appears that the $\mathrm{pH}$ between cytosol and intracellular compartments actually regulates cytosolic levels of chemotherapeutics and thus their level of cytotoxicity. For example, MCF-7 breast cancer cells have a decreased $\mathrm{pH}$ gradient due to the abnormal acidification of organelles, as well as the fragmentation and dispersion of the TGN (Trans Golgi Network) and endosomes throughout the cells [96, 97]. On the contrary, the adriamycin-resistant cell line derived from MCF-7 exhibits normal organelle acidification and distribution, and also adriamycin accumulation in acidic organelles which is unlikely for drug-sensitive MCF-7 cells. However, the disruption of vesicular acidification achieved by treatments with ionophores (nigericin and monensin) or with V-ATPase inhibitors (bafilomycin A1 and concanamycin A), induces their resensitization to adriamycin [24]. This correlation between defects in organelles acidification and cells drug-sensitivity has also been confirmed in the study with tamoxifen. It has been reported that tamoxifen is able to resensitize drug-resistant tumor cells to other chemotherapeutic drugs. It selectively alkalinizes acidified organelles without altering cytoplasmic $\mathrm{pH}$ and thus causes redistribu- tion of weak base chemotherapeutics from organelles to the nucleus [24].

\section{CURRENT \& FUTURE DEVELOPMENTS:}

In this review, we have summarized how drug molecular properties, membrane mechanics, drug transporters, and the $\mathrm{pH}$ of cytosol and of intracellular compartments interact together to participate in uptake and extrusion of anticancer drugs in cells. In particular, we have tried to focus on three important points: firstly quantitative law of drug distribution based on this set of parameters can be established and fit well with data from the literature. Secondly, proton concentration exerts a pleiotropic effect on anticancer drug sensitivity, by acting on drug ionization, on membrane tension and by setting the $\mathrm{pH}$ of cellular and subcellular compartments through pump and leak transporters. Thirdly, based on the previous elements, it is easy to understand why the pumping out of anticancer drugs from the cell in drug resistance, if alone, would be relatively marginal compared to these multiple effects of $\mathrm{pH}$ on the membrane. Although other more complex biological mechanisms involved in drug resistance, e.g. anti-apoptotic stimuli linked to cytosolic alkalization [98] might take place, and are certainly not ruled out, the different assumptions presented in this manuscript are supported by experimental evidence. Conversely, it is easily understandable that targeting the plasma membrane, $\mathrm{pH}$ regulation or intracellular compartments to eliminate tumor cells is of course not by itself sufficient but might potentiate existing treatments. Finally, as drugs used in multiple diseases bear an important hydrophobic part and/or have to act on intracellular targets, it is important to point out that the different concepts highlighted in this review article are relevant in a broader context than cancer chemotherapy.

Finally, it is worth noting that although drug chemicals targeting $\mathrm{pH}$ regulators/ions channels or transporters exist [99], nothing has been done to determine whether the membrane mechanical properties can be targeted by drugs and thus manipulated. Although lipids or cholesterol sequestration/differential synthesis or metabolism $[100,101]$ might be a solution to overcome the membrane packing problem and MDR, the problem remains, today, entirely open and is in need of complementary investigations.

\section{IMPORTANCE OF RECENT PATENTS FOR THE PHYSICAL BIOLOGY OF DRUG RESISTANCE:}

What has been underlined so far is that change in cytosolic $\mathrm{pH}$ is central to driving drug resistance. It follows that every inventions, methods, techniques and design to reverse the cytosolic $\mathrm{pH}$ [102] should be emphasized. In particular, new chemicals acting on sodium -proton exchanger (NHE) [103, 104], ATP synthase [105-107] or the proton-linked monocarboxylate transporter (MCT) [108] could be used to prevent or reverse MDR. Selectivity would be achieved using the MCT inhibitors, since these transporters are found in a wide variety tumor cells and tissues, but much less so in normal tissues [109, 110]. For the MCT, two inhibitors have been discovered by AstraZeneca, which are active in the 
nanomolar range. Preliminary data using one of these, compound 8 , indicates it does indeed have a pronounced effect on $\mathrm{pH}_{\mathrm{i}}$, in experiments using neuroblastoma cells (data not shown). In addition, the NHE is far more active in an acidic microenvironments, which is what you have in the tumor microenvironment [111]. Since it is expected that any inhibitors of these transporters may cause upregulation of noninhibited transporters, ultimately a cocktail (mixture) of inhibitors may be necessary to maintain the anti-tumor effect. The best NHE inhibitor available, already used clinically for other applications in the UK, is cariporide [112].

An additional transporter, ATP synthase, was first identified by the Pizzo research group [113, 114]. This transporter is found on endothelial cells in the tumor microenvironment and on tumor cells themselves. It is oriented such that ATP is generated on the outer surface of cells. This transporter is inhibited by angiostatin, but when angiostatin was tried clinically, it was found to be cleared from the circulation with a half-life of less than 15 minutes. A suitable more stable inhibitor of this transporter is reservatrol (Wahl, unpublished observations). This ingredient of red grapes and red wine is currently being touted in the United States as an antiaging remedy. In experiements measuring intracellular $\mathrm{pH}$ in live cells, it behaved exactly like angiostatin, bringing about an intracellular $\mathrm{pH}$ decrease when coupled with acute extracellular acidification in tumor cells and endothelial cells.

All of these inhibitors could be key in manipulating intracellular $\mathrm{pH}$ and therefore the multi-drug resistance phenotype.

\section{ACKNOWLEDGEMENTS}

All authors contributed differently but equally to this review.

\section{CONFLICT OF INTEREST}

None to declare.

\section{REFERENCES}

[1] Gajate C, Mollinedo F. Biological activities, mechanisms of action and biomedical prospect of the antitumor ether phospholipid ET$18-\mathrm{OCH}(3)$ (edelfosine), a proapoptotic agent in tumor cells. Curr Drug Metab 2002; 3(5): 491-525.

[2] Torigoe $\mathrm{T}$, Izumi $\mathrm{H}$, Ise $\mathrm{T}$, Murakami $\mathrm{T}$, Uramoto $\mathrm{H}$, Ishiguchi $\mathrm{H}$, et al. Vacuolar $\mathrm{H}(+)$-ATPase: functional mechanisms and potential as a target for cancer chemotherapy. Anticancer Drugs 2002; 13(3): 237-43.

[3] Harguindey S, Reshkin SJ, Orive G, Arranz JL, Anitua E. Growth and trophic factors, $\mathrm{pH}$ and the $\mathrm{Na}+\mathrm{H}+$ exchanger in Alzheimer's disease, other neurodegenerative diseases and cancer: new therapeutic possibilities and potential dangers. Curr Alzheimer Res 2007; 4(1): 53-65.

[4] Devaux PF. Is lipid translocation involved during endo- and exocytosis? Biochimie 2000; 82(5): 497-509.

[5] Pomorski T, Menon AK. Lipid flippases and their biological functions. Cell Mol Life Sci 2006; 63(24): 2908-21.

[6] Seigneuret M, Devaux PF. ATP-dependent asymmetric distribution of spin-labeled phospholipids in the erythrocyte membrane: relation to shape changes. Proc Natl Acad Sci USA 1984; 81(12): 3751-5.

[7] Devaux PF, Zachowski A, Morrot G, Cribier S, Fellmann P, Geldwerth $\mathrm{D}$, et al. Control of the transmembrane phospholipid distribution in eukaryotic cells by aminophospholipid translocase. Biotechnol Appl Biochem 1990; 12(5): 517-22.

[8] Farge E, Devaux PF. Shape changes of giant liposomes induced by an asymmetric transmembrane distribution of phospholipids. Biophys J 1992; 61(2): 347-57.

[9] Miao L, Seifert U, Wortis M, Dobereiner HG. Budding transitions of fluid-bilayer vesicles: The effect of area-difference elasticity. Phys Rev E Stat Phys Plasmas Fluids Relat Interdiscip Topics 1994; 49(6): 5389-407.

[10] Cribier S, Sainte-Marie J, Devaux PF. Quantitative comparison between aminophospholipid translocase activity in human erythrocytes and in K562 cells. Biochim Biophys Acta 1993; 1148(1): 85-90.

[11] Farge E, Ojcius DM, Subtil A, Dautry-Varsat A. Enhancement of endocytosis due to aminophospholipid transport across the plasma membrane of living cells. Am J Physiol 1999; 276(3 Pt 1): C72533.

[12] Rauch C, Farge E. Endocytosis switch controlled by transmembrane osmotic pressure and phospholipid number asymmetry. Biophys J 2000; 78(6): 3036-47.

[13] Nossal R, Zimmerberg J. Endocytosis: curvature to the ENTH degree. Curr Biol 2002; 12(22): R770-2.

[14] Itoh T, De Camilli P. BAR, F-BAR (EFC) and ENTH/ANTH domains in the regulation of membrane-cytosol interfaces and membrane curvature. Biochimica et biophysica acta 2006; 1761(8): 897-912.

[15] Rauch C, Pluen A. Multi drug resistance-dependent "vacuum cleaner" functionality potentially driven by the interactions between endocytosis, drug size and Pgp-like transporters surface density. Eur Biophys J 2007; 36(2): 121-31.

[16] Rauch C. Toward a mechanical control of drug delivery. On the relationship between Lipinski's 2 nd rule and cytosolic $\mathrm{pH}$ changes in doxorubicin resistance levels in cancer cells: A comparison to published data. Eur Biophys J 2009; 38(7): 829-46.

[17] Rauch C. On the relationship between drug's size, cell membrane mechanical properties and high levels of multi drug resistance: A comparison to published data. Eur Biophys J 2009; 38(4): 537-46.

[18] Regev R, Yeheskely-Hayon D, Katzir H, Eytan GD. Transport of anthracyclines and mitoxantrone across membranes by a flip-flop mechanism. Biochem Pharmacol 2005; 70(1): 161-9.

[19] Cirilli M, Bachechi F, Ughetto G, Colonna FP, Capobianco ML. Interactions between morpholinyl anthracyclines and DNA. The crystal structure of a morpholino doxorubicin bound to d(CGTACG). J Mol Biol 1993; 230(3): 878-89.

[20] Heijn M, Roberge S, Jain RK. Cellular membrane permeability of anthracyclines does not correlate with their delivery in a tissueisolated tumor. Cancer Res 1999; 59(17): 4458-63.

[21] Bloom M, Evans E, Mouritsen OG. Physical properties of the fluid lipid-bilayer component of cell membranes: A perspective. Q Rev Biophys 1991; 24(3): 293-397.

[22] Devaux PF, Zachowski A, Favre E, Fellmann P, Cribier S, Geldwerth D, et al. Energy-dependent translocation of aminophospholipids in the erythrocyte membrane. Biochimie 1986; 68(3): 383-93.

[23] Farge E. Increased vesicle endocytosis due to an increase in the plasma membrane phosphatidylserine concentration. Biophys $\mathrm{J}$ 1995; 69(6): 2501-6.

[24] Altan N, Chen Y, Schindler M, Simon SM. Tamoxifen inhibits acidification in cells independent of the estrogen receptor. Proc Natl Acad Sci USA 1999; 96(8): 4432-7.

[25] Sehested M, Skovsgaard T, van Deurs B, Winther-Nielsen H Increased plasma membrane traffic in daunorubicin resistant P388 leukaemic cells. Effect of daunorubicin and verapamil. Br J Cancer 1987; 56(6): 747-51

[26] Rauch C, Pluen A, Foster N, Loughna P, Mobasheri A, LagadicGossmann D, et al. On some aspects of the thermodynamic of membrane recycling mediated by fluid phase endocytosis: Evaluation of published data and perspectives. Cell Biochem Biophys 2010; 56(2-3): 73-90.

[27] Ambudkar SV, Dey S, Hrycyna CA, Ramachandra M, Pastan I, Gottesman MM. Biochemical, cellular, and pharmacological aspects of the multidrug transporter. Annu Rev Pharmacol Toxicol 1999; 39: 361-98. 
[28] Bornmann WG, Roepe PD. Analysis of drug transport kinetics in multidrug-resistant cells using a novel coumarin-vinblastine compound. Biochemistry 1994; 33(42): 12665-75.

[29] Eytan GD. Mechanism of multidrug resistance in relation to passive membrane permeation. Biomed Pharmacother 2005; 59(3): 90-7.

[30] Germann UA. P-glycoprotein--a mediator of multidrug resistance in tumour cells. Eur J Cancer 1996; 32A(6): 927-44.

[31] Nielsen D, Maare C, Skovsgaard T. Influx of daunorubicin in multidrug resistant Ehrlich ascites tumour cells: Correlation to expression of P-glycoprotein and efflux. Influence of verapamil. Biochem Pharmacol 1995; 50(4): 443-50.

[32] Ramu A, Pollard HB, Rosario LM. Doxorubicin resistance in P388 leukemia--evidence for reduced drug influx. Int J Cancer 1989; 44(3): 539-47.

[33] Raviv Y, Pollard HB, Bruggemann EP, Pastan I, Gottesman MM. Photosensitized labeling of a functional multidrug transporter in living drug-resistant tumor cells. J Biol Chem 1990; 265(7): 397580 .

[34] Sharom FJ. The P-glycoprotein efflux pump: How does it transport drugs? J Membr Biol 1997; 160(3): 161-75.

[35] Sirotnak FM, Yang CH, Mines LS, Oribe E, Biedler JL. Markedly altered membrane transport and intracellular binding of vincristine in multidrug-resistant Chinese hamster cells selected for resistance to vinca alkaloids. J Cell Physiol 1986; 126(2): 266-74.

[36] Spoelstra EC, Westerhoff HV, Dekker H, Lankelma J. Kinetics of daunorubicin transport by P-glycoprotein of intact cancer cells. Eur J Biochem 1992; 207(2): 567-79.

[37] Stein WD, Cardarelli C, Pastan I, Gottesman MM. Kinetic evidence suggesting that the multidrug transporter differentially handles influx and efflux of its substrates. Mol Pharmacol 1994; 45(4): 763-72.

[38] Rudnick J, Gaspari G. Elements of the Random Walk. Cambridge: Cambridge University Press; 2004.

[39] Ferte J. Analysis of the tangled relationships between Pglycoprotein-mediated multidrug resistance and the lipid phase of the cell membrane. Eur J Biochem / FEBS 2000; 267(2): 277-94.

[40] Colin M, Madoulet C, Warren L, Jardillier JC. Alterations of vinblastine influx in multidrug-resistant lymphoblastic leukaemic CEM cells. Anticancer Res 1996; 16(1): 407-12.

[41] Biedler JL, Riehm H. Cellular resistance to actinomycin-D in chinese hamster cells in vitro - cross-resistance, radioautographic, and cytogenetic studies. Cancer Res 1970; 30(4): 1174-84.

[42] Selassie CD, Hansch C, Khwaja TA. Structure Activity Relationships of Multidrug Resistance. In: Curtius H-C, Ghisla S, Blau N, editors. Chemistry and Biology of Pteridines, 1989: Pteridines and Folic Acid Derivatives. $9^{\text {th }}$ International Symposium on Pteridines and Folic Acid Derivatives Chemical, Biological, and Clinical Aspects; 1989 Sep 3-8; Zurich, Switzerland. Berlin: Walter de Gruyter and Co.; 1990, pp. 1217-20.

[43] Selassie CD, Hansch C, Khwaja TA. Structure-activityrelationships of antineoplastic agents in multidrug resistance. J Med Chem 1990; 33(7): 1914-9.

[44] Seelig A. The role of size and charge for blood-brain barrier permeation of drugs and fatty acids. J Mol Neurosci2007; 33(1): $32-41$.

[45] Harguindey S, Orive G, Luis Pedraz J, Paradiso A, Reshkin SJ. The role of $\mathrm{pH}$ dynamics and the $\mathrm{Na}^{+} / \mathrm{H}^{+}$antiporter in the etiopathogenesis and treatment of cancer. Two faces of the same coin--one single nature. Biochim Biophys Acta 2005; 1756(1): 124.

[46] Harguindey S, Pedraz JL, Garcia Canero R, Perez de Diego J, Cragoe EJ, Jr. Hydrogen ion-dependent oncogenesis and parallel new avenues to cancer prevention and treatment using a $\mathrm{H}(+)$ mediated unifying approach: $\mathrm{pH}$-related and $\mathrm{pH}$-unrelated mechanisms. Crit Rev Oncog 1995; 6(1): 1-33.

[47] Perona R, Serrano R. Increased $\mathrm{pH}$ and tumorigenicity of fibroblasts expressing a yeast proton pump. Nature 1988; 334(6181): 438-40.

[48] Reshkin SJ, Bellizzi A, Caldeira S, Albarani V, Malanchi I, Poignee $\mathrm{M}$, et al. $\mathrm{Na}^{+} / \mathrm{H}^{+}$exchanger-dependent intracellular alkalinization is an early event in malignant transformation and plays an essential role in the development of subsequent transformation-associated phenotypes. FASEB J 2000; 14(14): 2185-97.
[49] Hanahan D, Weinberg RA. The hallmarks of cancer. Cell 2000; 100(1): 57-70.

[50] Webb SD, Sherratt JA, Fish RG. Mathematical modelling of tumour acidity: regulation of intracellular $\mathrm{pH}$. J Theor Biol 1999; 196(2): 237-50.

[51] Roepe PD. pH and multidrug resistance. Novartis Found Symp 2001; 240: 232-47; discussion 47-50.

[52] Raghunand N, Gillies RJ. pH and chemotherapy. Novartis Found Symp 2001; 240: 199-211; discussion 65-8.

[53] Chen Q, Benson RS, Whetton AD, Brant SR, Donowitz M, Montrose $\mathrm{MH}$, et al. Role of acid/base homeostasis in the suppression of apoptosis in haemopoietic cells by $\mathrm{v}-\mathrm{Abl}$ protein tyrosine kinase. J Cell Sci 1997; 110 (Pt 3): 379-87.

[54] Goossens JF, Henichart JP, Dassonneville L, Facompre M, Bailly C. Relation between intracellular acidification and camptothecininduced apoptosis in leukemia cells. Eur J Pharm Sci 2000; 10(2): 125-31.

[55] Roepe PD, Wei LY, Cruz J, Carlson D. Lower electrical membrane potential and altered $\mathrm{pHi}$ homeostasis in multidrug-resistant (MDR) cells: Further characterization of a series of MDR cell lines expressing different levels of P-glycoprotein. Biochemistry 1993; 32(41): $11042-56$

[56] Simon S. The multiple mechanisms of multidrug resistance and cellular pH. Novartis Found Symp 2001; 240: 269-81; discussion 82-9.

[57] Fidler IJ, Ellis LM. The implications of angiogenesis for the biology and therapy of cancer metastasis. Cell 1994; 79(2): 185-8.

[58] El Awad B, Kreft B, Wolber EM, Hellwig-Burgel T, Metzen E, Fandrey $\mathrm{J}$, et al. Hypoxia and interleukin-lbeta stimulate vascular endothelial growth factor production in human proximal tubular cells. Kidney Int 2000; 58(1): 43-50.

[59] D'Arcangelo D, Facchiano F, Barlucchi LM, Melillo G, Illi B, Testolin L, et al. Acidosis inhibits endothelial cell apoptosis and function and induces basic fibroblast growth factor and vascular endothelial growth factor expression. Circ Res 2000; 86(3): 312-8.

[60] Laurencot CM, Andrews PA, Kennedy KA. Inhibitors of intracellular $\mathrm{pH}$ regulation induce cisplatin resistance in EMT6 mouse mammary tumor cells. Oncol Res 1995; 7(7-8): 363-9.

[61] Chau Q, Stewart DJ. Cisplatin efflux, binding and intracellular $\mathrm{pH}$ in the HTB56 human lung adenocarcinoma cell line and the E-8/0.7 cisplatin-resistant variant. Cancer Chemother Pharmacol 1999; 44(3): 193-202.

[62] Barry MA, Reynolds JE, Eastman A. Etoposide-induced apoptosis in human HL-60 cells is associated with intracellular acidification. Cancer Res 1993; 53(10 Suppl): 2349-57.

[63] De Milito A, Fais S. Tumor acidity, chemoresistance and proton pump inhibitors. Future Oncol 2005; 1(6): 779-86.

[64] Di Sario A, Bendia E, Omenetti A, De Minicis S, Marzioni M, Kleemann HW, et al. Selective inhibition of ion transport mechanisms regulating intracellular $\mathrm{pH}$ reduces proliferation and induces apoptosis in cholangiocarcinoma cells. Dig Liver Dis 2007; 39(1): 60-9.

[65] Murakami T, Shibuya I, Ise T, Chen ZS, Akiyama S, Nakagawa M, et al. Elevated expression of vacuolar proton pump genes and cellular PH in cisplatin resistance. Int J Cancer 2001; 93(6): 86974 .

[66] Keizer HG, Joenje H. Increased cytosolic $\mathrm{pH}$ in multidrug-resistant human lung tumor cells: Effect of verapamil. J Nat Cancer Inst 1989; 81(9): 706-9.

[67] Roepe PD. The role of the MDR protein in altered drug translocation across tumor cell membranes. Biochim Biophys Acta 1995; 1241(3): 385-405.

[68] Radvakova I, Mirossay A, Mojzis J, Mirossay L. The effect of 5'(N,N-dimethyl)-amiloride on cytotoxic activity of doxorubicin and vincristine in CEM cell lines. Physiol Res 2001; 50(3): 283-7.

[69] Goda K, Balkay L, Marian T, Tron L, Aszalos A, Szabo G, Jr. Intracellular $\mathrm{pH}$ does not affect drug extrusion by P-glycoprotein. J Photochem Photobiol B 1996; 34(2-3): 177-82.

[70] Altenberg GA, Young G, Horton JK, Glass D, Belli JA, Reuss L. Changes in intra- or extracellular $\mathrm{pH}$ do not mediate $\mathrm{P}$ glycoprotein-dependent multidrug resistance. Proc Natl Acad Sci USA 1993; 90(20): 9735-8. 
[71] Alberts B, Bray D, Lewis J, Raff M, Roberts K, Watson JD. Biologie Moleculaire de La Cellule. Inc. GP, Editor. New York 1994.

[72] Petelska AD, Figaszewski ZA. Effect of $\mathrm{pH}$ on the interfacial tension of bilayer lipid membrane formed from phosphatidylcholine or phosphatidylserine. Biochimica et Biophysica Acta 2002; 1561(2): 135-46.

[73] Petrache HI, Zemb T, Belloni L, Parsegian VA. Salt screening and specific ion adsorption determine neutral-lipid membrane interactions. Proc Natl Acad Sci USA 2006; 103(21): 7982-7.

[74] Victorov AV, Janes N, Taraschi TF, Hoek JB. Packing constraints and electrostatic surface potentials determine transmembrane asymmetry of phosphatidylethanol. Biophysical J 1997; 72(6): 2588-98

[75] Mellman I, Fuchs R, Helenius A. Acidification of the endocytic and exocytic pathways. Annu Rev Biochem 1986; 55: 663-700.

[76] Anderson RG, Pathak RK. Vesicles and cisternae in the trans Golgi apparatus of human fibroblasts are acidic compartments. Cell 1985; 40(3): 635-43.

[77] Mellman I. The importance of being acid: The role of acidification in intracellular membrane traffic. J Exp Biol 1992; 172: 39-45.

[78] Bayer N, Schober D, Prchla E, Murphy RF, Blaas D, Fuchs R. Effect of bafilomycin A1 and nocodazole on endocytic transport in HeLa cells: Implications for viral uncoating and infection. J Virol 1998; 72(12): 9645-55.

[79] van Deurs B, Holm PK, Sandvig K. Inhibition of the vacuolar $\mathrm{H}(+)$-ATPase with bafilomycin reduces delivery of internalized molecules from mature multivesicular endosomes to lysosomes in HEp-2 cells. Eur J Cell Biol 1996; 69(4): 343-50.

[80] Weisz OA. Acidification and protein traffic. Int Rev Cytol 2003; 226: 259-319

[81] Hurtado-Lorenzo A, Skinner M, El Annan J, Futai M, Sun-Wada GH, Bourgoin S, et al. V-ATPase interacts with ARNO and Arf6 in early endosomes and regulates the protein degradative pathway. Nat Cell Biol 2006; 8(2): 124-36.

[82] Anbari M, Root KV, Van Dyke RW. Role of Na,K-ATPase in regulating acidification of early rat liver endocytic vesicles. Hepatology 1994; 19(4): 1034-43.

[83] Cain CC, Sipe DM, Murphy RF. Regulation of endocytic $\mathrm{pH}$ by the $\mathrm{Na}^{+}, \mathrm{K}^{+}$-ATPase in living cells. Proc Natl Acad Sci USA 1989; 86(2): 544-8.

[84] Fuchs R, Schmid S, Mellman I. A possible role for $\mathrm{Na}^{+}, \mathrm{K}^{+}$-ATPase in regulating ATP-dependent endosome acidification. Proc Natl Acad Sci USA 1989; 86(2): 539-43.

[85] Grabe M, Oster G. Regulation of organelle acidity. J Gen Physiol 2001; 117(4): 329-44.

[86] Hara-Chikuma M, Wang Y, Guggino SE, Guggino WB, Verkman AS. Impaired acidification in early endosomes of ClC-5 deficient proximal tubule. Biochem Biophys Res Commun 2005; 329(3): 941-6.

[87] Hara-Chikuma M, Yang B, Sonawane ND, Sasaki S, Uchida S, Verkman AS. ClC-3 chloride channels facilitate endosomal acidification and chloride accumulation. J Biol Chem 2005; 280(2): 1241-7.

[88] Jentsch TJ. Chloride and the endosomal-lysosomal pathway: emerging roles of CLC chloride transporters. J Physiol 2007; 578(Pt 3): 633-40.

[89] Mohammad-Panah R, Harrison R, Dhani S, Ackerley C, Huan LJ, Wang $\mathrm{Y}$, et al. The chloride channel $\mathrm{ClC}-4$ contributes to endosomal acidification and trafficking. J Biol Chem 2003; 278(31): 29267-77.

[90] Di A, Brown ME, Deriy LV, Li C, Szeto FL, Chen Y, et al. CFTR regulates phagosome acidification in macrophages and alters bactericidal activity. Nat Cell Biol 2006; 8(9): 933-44.

[91] Schapiro FB, Grinstein S. Determinants of the $\mathrm{pH}$ of the Golgi complex. J Biol Chem 2000; 275(28): 21025-32.

[92] Cherny VV, DeCoursey TE. pH-dependent inhibition of voltagegated $\mathrm{H}(+)$ currents in rat alveolar epithelial cells by $\mathrm{Zn}(2+)$ and other divalent cations. J Gen Physiol 1999; 114(6): 819-38.
[93] Wu MM, Grabe M, Adams S, Tsien RY, Moore HP, Machen TE. Mechanisms of $\mathrm{pH}$ regulation in the regulated secretory pathway. J Biol Chem 2001; 276(35): 33027-35.

[94] Simon SM, Schindler M. Cell biological mechanisms of multidrug resistance in tumors. Proc Natl Acad Sci USA 1994; 91(9): 3497 504.

[95] Jiang LW, Maher VM, McCormick JJ, Schindler M. Alkalinization of the lysosomes is correlated with ras transformation of murine and human fibroblasts. J Biol Chem 1990; 265(9): 4775-7.

[96] Schindler M, Grabski S, Hoff E, Simon SM. Defective pH regulation of acidic compartments in human breast cancer cells (MCF-7) is normalized in adriamycin-resistant cells (MCF-7adr). Biochemistry 1996; 35(9): 2811-7.

[97] Altan N, Chen Y, Schindler M, Simon SM. Defective acidification in human breast tumor cells and implications for chemotherapy. J Exp Med 1998; 187(10): 1583-98

[98] Lagadic-Gossmann D, Huc L, Lecureur V. Alterations of intracellular $\mathrm{pH}$ homeostasis in apoptosis: origins and roles. Cell Death Differ 2004; 11(9): 953-61.

[99] Weigele, M., Dalgarno, D.C., Iuliucci, J., Keenan, T.P., Sawyer, T.K. Proton pump inhibitors. US20020010159 (2002).

[100] Boffelli, D., Hauser, H. Amphipathic molecules as cholesterol and other lipid uptake inhibitors. US20010005714 (2001).

[101] Mangelsdorf, D.J., Repa, J.J., Turley, S.D., Dietschy, J.M. Compositions and methods of modulating cholesterol metabolism. US6835866 (2004)

[102] Giles, I. B. Ionic cancer therapy and methods for using same in the treatment of tumors and metastasis US20040253323 (2004)

[103] Gorin, A. F., Nantz, H. M. Amino acid and peptide conjugates of amiloride and methods of use thereof. US7863415 (2010)

[104] Uemoto, K., Takayanagi, K., Kazayama, S. Cyclohepta[b]pyridine3 -carbonylguanidine derivative and pharmaceutical product containing same substituted guanide derivatives. US7875625 (2006).

[105] Boyd, R.M., Gustafson, R.K. Chondropsin-class antitumor VATPase inhibitor compounds, compositions and methods of use thereof. US7521475 (2009).

[106] Boyd, R.M., Gustafson, R.K. Chondropsin-class antitumor VATPase inhibitor compounds, compositions and methods of use thereof. US7205334 (2009).

[107] Paglin, S., Yahalom, J., Hollister, T., Delohery, T. Inhibition of vacuolar proton ATPase activity and/or the modulation of acidic organelle function sensitizes cells to radiation, chemotherapy and biological agents. US6982252 (2001)

[108] Sullivan, M., Murray, C.M., Hutchinson, R., Donald, D.K., Jackson, C.G., Jackson, P.J., Bantick, J.R., Cook, I.D. Inhibitors of monocarboxylate transport. US0072746 (2004)

[109] Wahl ML, Owen JA, Burd R, Herlands RA, Nogami SS, Rodeck $\mathrm{U}$, et al. Regulation of intracellular $\mathrm{pH}$ in human melanoma: Potential therapeutic implications. Mol Cancer Ther 2002; 1(8): 617-28.

[110] Sonveaux P, Vegran F, Schroeder T, Wergin MC, Verrax J, Rabbani ZN, et al. Targeting lactate-fueled respiration selectively kills hypoxic tumor cells in mice. J Clin Invest 2008; 118(12): 3930-42.

[111] Pouyssegur J, Franchi A, Pages G. pHi, aerobic glycolysis and vascular endothelial growth factor in tumour growth. Novartis Found Symp 2001; 240: 186-96; discussion 96-8.

[112] Scholz W, Albus U, Counillon L, Gogelein H, Lang HJ, Linz W, et al. Protective effects of HOE642, a selective sodium-hydrogen exchange subtype 1 inhibitor, on cardiac ischaemia and reperfusion. Cardiovasc Res 1995; 29(2): 260-8.

[113] Moser TL, Stack MS, Asplin I, Enghild JJ, Hojrup P, Everitt L, et al. Angiostatin binds ATP synthase on the surface of human endothelial cells. Proc Natl Acad Sci USA 1999; 96(6): 2811-6.

[114] Moser TL, Kenan DJ, Ashley TA, Roy JA, Goodman MD, Misra $\mathrm{UK}$, et al. Endothelial cell surface F1-F0 ATP synthase is active in ATP synthesis and is inhibited by angiostatin. Proc Natl Acad Sci USA 2001; 98(12): 6656-61. 